Eppler, Martin J. \& Bresciani, Sabrina (2013) Visualization in Management: From Communication to Collaboration. A Response to Zhang. Journal of Visual Languages and Computing, 24 (2). 146-149. ISSN 1045-926X

Available online at: http://www.sciencedirect.com/science/article/pii/S1045926X13000037

\title{
Visualization in Management: From Communication to Collaboration. A Response to Zhang
}

Martin J. Eppler, Sabrina Bresciani

University of St. Gallen

$=\mathrm{mcm}$ Institute for Media and Communications Management

Blumenbergplatz 9

9000 St. Gallen

Switzerland

martin.eppler@unisg.ch ; sabrina.bresciani@unisg.ch

\section{Introduction: Visualizing Management - beyond Communicating Charts}

It is an idea whose time has come: the use of visualization in management. As management is an area where complex information must be used for a variety of tasks that are often performed under extreme time pressure, visualization appears like an obvious strategy to cope with the risks of information overload. In addition, managers often cannot rely on their own expertise alone. They need input from a wide spectrum of specialists and thus at times struggle to integrate knowledge from different sources and use it for idea generation, decision making or planning. To do so, they rely on what many researchers today call socio-material or visual practices [1,2], emphasizing the activity of visualizing over the pictures that are generated. These visual practices consist of jointly and iteratively visualizing facts, analyses, insights and experiences, and consequently improve the quality of collaboration. We thus only partly agree with Zhang's [3] assessment that the use of visualization in management activities has been limited to statistical charts. While it is probably the case that the most widely used format of visualization today is the numeric or quantitative chart, we have witnessed an increasing use of qualitative visualizations (i.e., conceptual diagrams, metaphors, or sketches) in the management world, as illustrated by recent management bestsellers on the topic [46]. More importantly, while Zhang sees the biggest benefit of visual languages in the communication of complex information, we believe that the act of visualizing is at least as important as the visualization outcome itself. The power of visualization to enable effective and seamless collaboration (especially across disciplinary boundaries) even exceeds its potential to improve communication. In fact, limiting the use of visualization to the mere presentation aspect would not do it justice for the realm of management. In this contribution, we would thus like to build on Zhang's examples of managerial visualization and show that it can provide even more value when used as a collaboration catalyst, rather than just an accessible presentation format. To do so, we first provide an overview on the realm of management visualization, extending the scope beyond charts and diagrams, and then derive future research avenues for this promising field of inquiry. In the final section we draw some preliminary conclusions and invite our fellow researchers to explore the research challenges in this field in an interdisciplinary manner. 


\section{The Realm of Management Visualization}

As illustrated in Zhang's paper, visualization can be useful for many domains of management, ranging from finance, human resources, to general management and strategy. Zhang focuses on the use of statistical charts like scatter plots, and (interactive) diagrams, such as social network depictions, InfoShapes or simple box and arrow diagrams. Zhang's examples, although instructive, may represent a too narrow view of the emerging field of management visualization, as they are limited to simple forms of diagramming and charting. In our research, however, we discovered that the visual languages employed by managers today are much richer. They also include ad-hoc conceptual hand drawings and sketches, rich visual metaphors, as well as more elaborate forms of visualizing such as immersive 3D environments populated by Avatars that represent managers in decision, training or creativity settings. The figures below show typical examples of each of these visualization genres.
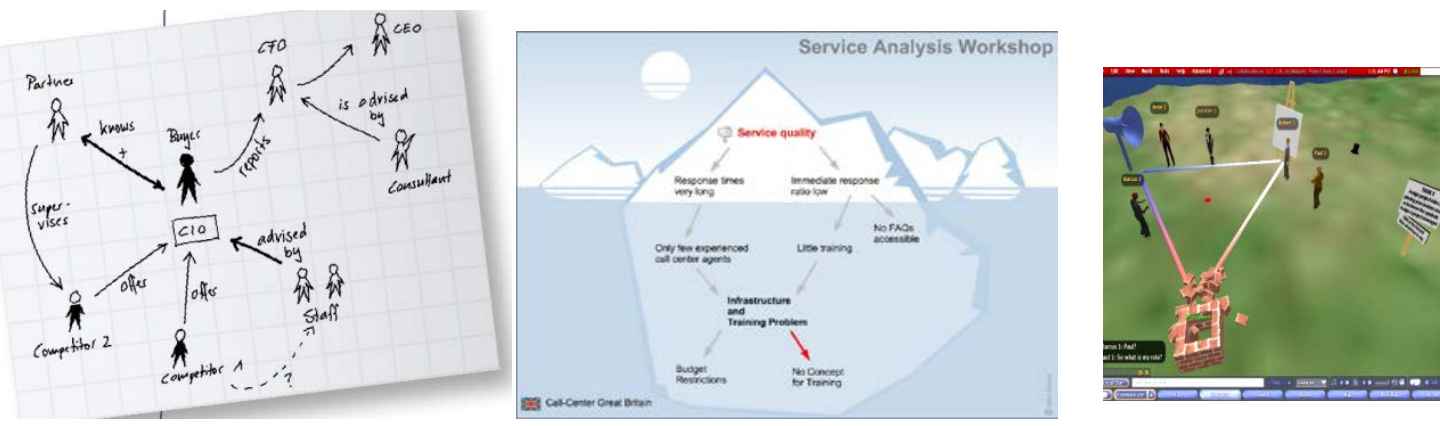

Figures 1, 2, and 3: Examples of managerial visualizations beyond classic diagrams and charts: sketch, visual metaphor, 3D setting (sources: [7-9]).

These visualization formats can be used in different management functions and for diverse knowledge tasks, ranging from idea generation, decision making, planning or learning, to knowledge sharing and learning. This classification is based on McGrath's circumplex model of group tasks [10] and adapted to the management context where learning and knowledge sharing is a particularly crucial task. In the table below (Tab. 1), we provide an overview of the research conducted on these visual formats (for a classification see: [11]), as concerns their use for core management tasks. The table shows that there is indeed a discussion on managerial visualization beyond data representation formats.

\begin{tabular}{|l|l|l|l|l|l|}
\hline $\begin{array}{l}\text { VISUALIZATION } \\
\text { FORMAT/ } \\
\text { Management Tasks: }\end{array}$ & SKETCHING & $\begin{array}{l}\text { VISUAL } \\
\text { METAPHORS }\end{array}$ & DIAGRAMS & CHARTS & 3D WORLDS \\
\hline Idea generation & {$[4,7]$} & {$[12]$} & {$[13,14]$} & & {$[15]$} \\
\hline Decision making & {$[16,17]$} & {$[18]$} & {$[19-22]$} & {$[23,24]$} & {$[9]$} \\
\hline Planning & {$[5]$} & {$[25]$} & {$[26]$} & {$[27,28]$} & \\
\hline $\begin{array}{l}\text { Learning, knowledge } \\
\text { transfer/sharing }\end{array}$ & {$[4]$} & {$[29,8]$} & {$[30-32]$} & {$[23,33]$} & {$[34]$} \\
\hline
\end{tabular}

Table 1: Research evidence on visualization formats for specific management tasks.

\section{Collaborating with the Help of Visuals}

If one sees images not just as data containers, but as collaboration tools for managers, the question arises how to best use them for this purpose and how to better understand their effects on collaboration? The visualization formats depicted in Figures 1 through 3 and positioned in the grid 
above indeed differ with regard to their collaborative characteristics, meaning that they provide diverse affordances for collaboration and communication based on their visual and interactive traits. To help managers answer these two questions and to distinguish and choose adequate visual support for their tasks, we have developed, based on Green's Cognitive Dimensions of Notations [35, 36], the notion of collaborative dimensions of visualization [37]. These dimensions can be used to describe the key features of a visual language and determine whether it is suitable for a certain management task or not. Table 2 gives an overview of these collaborative dimensions of visual representations.

\begin{tabular}{|ll|}
\hline Dimension & Definition \\
\hline Visual Impact & Extent to which a visualization is attractive and grabbing attention. \\
\hline Clarity & $\begin{array}{l}\text { Extent to which a visualization is self-explanatory and easily understandable with low } \\
\text { cognitive effort. }\end{array}$ \\
\hline $\begin{array}{l}\text { Perceived } \\
\text { Finishedness }\end{array}$ & $\begin{array}{l}\text { Extent to which the visualization resembles a final, polished product [38] (and hence } \\
\text { inhibits or invites modifications). }\end{array}$ \\
\hline Directed Focus & Extent to which the structure of a visualization draws attention to the issue at hand. \\
\hline Inference Support & $\begin{array}{l}\text { Extent to which new insights are generated as a result of the constraints of a } \\
\text { visualization form. }\end{array}$ \\
\hline Modifiability & $\begin{array}{l}\text { Extent to which the items of a visualization can be dynamically altered in response to } \\
\text { the dynamics of a discussion [38]. }\end{array}$ \\
\hline $\begin{array}{l}\text { Discourse } \\
\text { management }\end{array}$ & Extent of the control of a visualization over a discussion flow and group dynamics. \\
\hline
\end{tabular}

Table 2: The Collaborative Dimensions of Visualization framework.

To illustrate the dimensions approach let us give the example of one of them, namely perceived finishedness. This dimension addresses the fact that some images are perceived as finished, while others give the impression of being work in progress. Typically, sketches have a low perceived finishedness, as they are understood to be in flux and 'under construction' (they look highly provisional). Diagrams and charts, by contrast - especially when presented in reports or slide presentations - tend to have a high perceived finishedness. This is a distinction that makes a difference with regard to collaboration: Whereas sketches invite revisions and iterative cooperative moves, polished diagrams are more likely to create a by-stander effect, as managers may feel reluctant to modify a seemingly perfect looking chart or diagram. Sketches may thus be a better visual language for managers in the idea generation phase than software-supported conceptual diagrams. How each visual representation differs from another with regard to these dimensions is the subject of our ongoing research. This and other future research avenues in the management visualization field are discussed in the final section of our article.

\section{A Research Agenda for Management Visualization}

As a fairly recent research domain at the intersection of management studies, computer science, psychology, and design, the field of management visualization offers many promising research avenues. As Zhang correctly points out, the role of aesthetics is but one of the conundrums facing visualization researchers and practitioners in the management context. In our view two main thrusts can be identified at this point in time. Both will help the field mature in terms of relevance and rigour. Regarding relevance we believe it is necessary that the field of management visualization broadens its scope and embraces novel visualization formats such as immersive worlds, electronic and live sketching, or visual metaphors. But this broadening should also take into account the new 
realities of managerial visualization and examine novel interfaces, such as mobile screens, gesturebased interfaces, or massively multi-user applications (already in use for innovation management). In this regard it seems imperative to us that researchers do not only focus on the representation of mass information and big data, but also on the use of visualization to help in the co-construction of knowledge. We believe that the field will further differentiate itself and that knowledge visualization will establish itself next to information visualization as a separate branch of visualization studies. With regard to rigor, a future research avenue lies in combining (and triangulating) experimental studies with on-site studies where real-life managers use visualization tools, as well as with longitudinal, context-rich case studies. In this way we can understand both the causalities of certain visual features, as well as the role of institutional contexts for the adoption or rejection of visual practices in management. With this dual focus on both the relevance and the rigor of managerial visualization, this emerging research field is not only an idea whose time has come, but also one that is here to stay.

\section{References}

[1] D. Nicolini, Studying visual practices in construction. Building Research \& Information, 35 (5), (2007) 576-580.

[2] J.K. Whyte, B. Ewenstein, M. Hales, J. Tidd, Visual practices and the objects used in design. Building Research \& Information, 35 (1), (2007) 18-27.

[3] K. Zhang, View Points: Using visual languages in management. Journal of Visual Languages \& Computing, 23 (6), (2012) 340-343.

[4] D. Roam, The back of the napkin: solving problems and selling ideas with pictures, Portfolio, New York, 2008.

[5] N. Duarte, Slide:ology. The art and science of creating great presentations, O'Reilly, Sebastopol CA, 2008.

[6] A. Osterwalder, Y. Pigneur, Business Model Generation: A Handbook for Visionaries, Game Changers, and Challengers, Wiley, 2010.

[7] M. J. Eppler, R. A. Pfister, Sketching at work, Schäffer-Poeschel, Stuttgart, 2012.

[8] S. Bresciani, M.J. Eppler, The Benefits of Synchronous Collaborative Information Visualization: Evidence from an Experimental Evaluation. IEEE Transactions on Visualization and Computer Graphics, 15 (6), (2009) 1073-1080.

[9] A. Schmeil, M. J Eppler, M. Gubler, An Experimental Comparison of 3D Virtual Environments and Text Chat as Collaboration Tools. Electronic Journal of Knowledge Management, 7 (5), (2009) 637646.

[10] J.E. McGrath, Groups: interaction and performance, Prentice-Hall, Englewood Cliffs NJ, 1984.

[11] M.J. Eppler, R. Burkhard, Visual Representations in Knowledge Management: Framework and Cases. Journal of Knowledge Management, 4 (11), (2007) 112-122.

[12] A. Okada, S. Buckingham Shum, T. Sherborne, T. (Eds.) Knowledge Cartography. Software Tools and Mapping Techniques, London, Springer, 2008.

[13] K. Platts, K.H. Tan, Strategy visualisation: knowing, understanding, and formulating. Management Decision, 42(5/6), (2004) 667-676.

[14] M.J. Eppler, F. Hoffmann, S. Bresciani, New Business Models Through Collaborative Idea Generation. International Journal of Innovation Management, Imperial College Press, 15 (6), (2011) 1323. 
[15] A. Schmeil, M.J. Eppler, S. de Freitas, S., A Structured Approach for Designing Collaboration Experiences for Virtual Worlds. Journal of the Association of Information Systems, 13 (10), (2012) 836-860.

[16] B. Tversky, M. Suwa, Thinking with sketches, in: A. Markman (Ed.), Tools for innovation, Oxford University Press, Oxford, 2009, pp. 75-84.

[17] R.A. Pfister, Does the medium matter?: An Experiment on the Impact of Collaboration on Visual Sales Sessions. In: IEEE Proceedings of 16th the International Conference on Information Visualization, 2012, pp. 343-348.

[18] R.A. Burkhard, Strategy Visualization: A New Research Focus in Knowledge Visualization and a Case Study. Proceedings of I-KNOW '05, J.UCS, Graz, Austria, 2005.

[19] J.H. Larkin, H. Simon, Why a Diagram is (Sometimes) Worth Ten Thousand Words. Cognitive Science, 11 (1987) 65-99.

[20] S.K. Card, J. Mackinlay, B. Shneiderman, Readings in Information Visualization: Using Vision to Think. Morgan Kaufmann, San Francisco, CA, 1999.

[21] A.F. Blackwell (Ed.), Thinking with Diagrams. Kluwer Academic, 2001.

[22] M. Craig, Thinking visually: business applications of fourteen core diagrams, Continuum, London, 2003.

[23] S. Few, Information Dashboard Design: The Effective Visual Communication of Data, O'Reilly Media, 2006.

[24] N.H. Lurie, C. H. Mason, Visual Representation: Implications for Decision Making. Journal of Marketing, 71(1), (2007) 160-177.

[25] D.G. Andriessen, Stuff or love? How metaphors direct our efforts to manage knowledge in organisations. Knowledge Management Research \& Practice, 6 (2008) 5-12.

[26] M. J. Eppler, K. Platts, Visual Strategizing: The Systematic Use of Visualization in the Strategic Planning Process. Long Range Planning, 42 (2009) 42-74.

[27] D.P. Tegarden, Business Information Visualization. Communications of the AIS, 1 (1999) 1-38.

[28] E.K. Yakura, Charting Time: Timelines as Temporal Boundary Objects. Academy of Management Journal, 45 (5), (2002) 956-970.

[29] M. Lux, The Iceberg Metaphor to Support the Knowledge Crystallization Cycle. Proceedings of the Information Visualization conference, London, U.K., 2000.

[30] D. Suthers, Collaborative Knowledge Construction through Shared Representations, Proceedings of the 38th Hawaii International Conference on System Sciences, 2005.

[31] C. Reed, G. Rowe, G., Araucaria: software for argument analysis, diagramming and representation. International Journal on Artificial Intelligence Tools, 13 (4), (2004) 961-979.

[32] A. Comi, M.J. Eppler, Assessing the Impact of Visual Facilitation on Inter-Organizational Collaboration: an Experimental Study. Journal of Universal Computer Science, 17(10), (2011) 14301454.

[33] E.R. Tufte, The visual display of quantitative information, Graphic Press, Cheshire, Connecticut, (1986).

[34] E. Hayes, Situated learning in virtual worlds: The learning ecology of Second Life. Proceedings of the Adult Education Research Conference, 2006.

[35] T.R.G. Green, M. Petre, Usability analysis of visual programming environments: a 'cognitive dimensions' framework, Journal of Visual Languages and Computing, 7 (1996) 131-174. 
[36] A.F. Blackwell, Ten years of cognitive dimensions in visual languages and computing. Journal of Visual Languages and Computing, 17 (4), (2006) 285-287.

[37] S. Bresciani, A.F. Blackwell, M.J. Eppler, A Collaborative Dimensions Framework: Understanding the Mediating Role of Conceptual Visualizations in Collaborative Knowledge Work. Proceedings of the 41st Hawaii International Conference on System Sciences, Big Island, HI (2008) pp. 180-189.

[38] C. Hundhausen, Using end user visualization environments to mediate conversations: A 'Communicative Dimensions' frame-work. Journal of Visual Languages and Computing, 16 (3), (2005) pp. 153-185. 